\title{
Illicit Drug Use Among Gym-Goers: a Cross- sectional Study of Gym-Goers in Sweden
}

\author{
Yasmina Molero ${ }^{1,2^{*}}$ D, Ann-Sofie Bakshi ${ }^{1}$ and Johanna Gripenberg ${ }^{1}$
}

\begin{abstract}
Background: The use of anabolic-androgenic steroids has increased among gym-goers, and it has been proposed that this may be part of a polysubstance use pattern that includes the use of illicit drugs. Still, epidemiological data on illicit drug use among gym-goers of both genders are meager. The aim of the present study was thus to examine the use of illicit drugs and its correlates in a large sample of men and women who engaged in weight training at gyms across Sweden.
\end{abstract}

Methods: In this cross-sectional study, a total of 1969 gym-goers who engaged in weight training in 54 gyms across Sweden were invited to fill in a questionnaire. The questionnaire included 25 items on background variables, weight training frequency, use of illicit drugs and doping substances, and non-medical use of benzodiazepines.

Results: Of the gym-goers, 19.6\% reported having ever used illicit drugs, 6.5\% reported use during the past 12 months, and $2.1 \%$ during the past 30 days. The most commonly used drug was cannabis, followed by cocaine, amphetamine, and ecstasy. Almost $40 \%$ of those who reported drug use had used more than one drug. Male participants and participants between 20 and 39 years of age made up the majority of users. Furthermore, $5.1 \%$ of the reported drug users had ever used a doping substance. There was an almost threefold higher odds ( $\mathrm{OR}=2.99,95 \% \mathrm{Cl}=1.16-7.66$, $p<0.023$ ) of doping use among people who had reported drug use as compared to non-users.

Conclusions: Training at gyms is typically considered a health-promoting behavior. However, our results revealed a slightly higher prevalence of illicit drug use among gym attendees as compared to the general population. Our findings may have captured an underrecognized group of young adult males who engage in weightlifting and use illicit drugs recreationally and/or as training aids. Developing knowledge is imperative in orientating preventive efforts among at-risk gym-goers.

Trial Registration: ISRCTN11655041

Keywords: Illicit drug use, Gym-goers, Anabolic-androgenic steroids, Cross-sectional study, Drug prevalence

\section{Key Points}

- Approximately one in five gym-goers report use of illicit drugs, most commonly cannabis and stimulants. The rates of drug use are higher among young adult males.

- Illicit drug use appears to be associated with the use of doping substances.

\footnotetext{
* Correspondence: yasmina.molero.samuelson@ki.se

'STAD, Centre for Psychiatry Research, Department of Clinical Neuroscience, Karolinska Institutet, \& Stockholm Health Care Services, Stockholm County Council, Norra Stationsgatan 69, SE-1113-64 Stockholm, Sweden

${ }^{2}$ Department of Medical Epidemiology and Biostatistics, Karolinska Institutet, Stockholm, Sweden
}

\section{Background}

Research shows that $65 \%$ of citizens in the European Union exercise at least once a week. Among this group, $30 \%$ exercise at sport clubs such as gyms and fitness centers [1]. In the USA, approximately $21 \%$ of adults reported exercising regularly [2], and more than 55 million memberships were purchased at health clubs and fitness centers in 2015 [3]. Exercise is a health-promoting activity associated with several benefits, including reduced 
risk of coronary heart disease, type 2 diabetes, breast and colon cancer, as well as premature mortality [4]. At the same time, there is growing evidence indicating that use of anabolic-androgenic steroids and non-medical use of prescription drugs have increased among gym-goers [5-7]. It has been proposed that this may be part of a polysubstance use pattern that involves other illicit drugs as well (e.g., cannabis and stimulants) [8]. Polysubstance use is associated with poorer mental health, sexual risk behavior, negative social consequences, and increased risk of infectious disease $[9,10]$. Furthermore, concurrent use of substances may have synergistic negative effects on brain function [9]. It has been suggested that doping prevention efforts should target gym-goers [11]. Given the association between doping substances and illicit drugs [8, 12-14], prevention efforts could therefore also address the use of illicit drugs [6]. Still, the research base on illicit drug use among gym-goers is limited, and developing knowledge is imperative in orientating preventive efforts.

Several studies have examined the use of illicit drugs among sportspeople through questionnaires or toxicological testing [15-23]. Results from these studies indicate elevated rates of illicit drug use, with cannabis and stimulants being the most commonly used drugs. However, these samples have been restricted to elite athletes or adolescent populations. Epidemiological studies focusing on illicit drug use among adult gym-goers are few in number. One study on 311 gym-going gay men in New York showed that $6-35 \%$ (depending on the type of drug) reported having used a drug during the past 6 months [24]. Another study on 1592 gay men who attended gyms in London showed that $56 \%$ reported having used an illicit drug during the past year [25]. It was proposed that many of these men do not frequent gyms as a health-promoting activity, but rather to achieve an idealized muscular, physically strong body. This was suggested to be indicative of a gay subculture that focuses on physical prowess and risk behaviors, including illicit drug use [24]. However, results from these two studies may be difficult to generalize to other gym-attending populations and across gender.

The present study is part of a larger on-going project entitled 100\% Pure Hard Training (100\% PHT) [26]. In the $100 \%$ PHT project, the prevalence of doping substances (i.e., anabolic-androgenic steroids and growth hormones) and other illicit drugs is measured among gym-goers who engage in weight training (i.e., work with free weights or machines), and the effect of a doping prevention programme (i.e., $100 \%$ PHT) is examined. In the present study, the use of illicit drugs, benzodiazepines, and doping substances among gym-goers was assessed using a cross-sectional design. This assessment was carried out prior to implementation of the prevention programme.
The overall aim of the study is to examine the use of illicit drugs in a large sample of men and women who engage in weight training at gyms across Sweden. Specifically, we conducted a cross-sectional examination of the (a) frequency and type of illicit drugs used, (b) frequency of non-medical use of benzodiazepines, (c) age and sex differences in illicit drug use, (d) associations between use of illicit drugs and weight training frequency, and (e) associations between use of illicit drugs and use of doping substances.

\section{Methods \\ Study Design}

The present study has a cross-sectional study design.

\section{Participants and Procedure}

In the spring of 2015, a questionnaire was distributed to gym-goers at 54 gyms in Sweden. The gyms were recruited either through Prevention of Doping in Sweden (PRODIS; a national network comprising governmental agencies, universities, county administrative boards, municipal prevention coordinators, representatives from the police force and gyms, the Swedish Sports Confederation, and the Swedish Anti-Doping Hotline) or through the research centre STAD (Stockholm Prevents Alcohol and Drug Problems). The questionnaire was distributed prior to implementation of the doping prevention programme $100 \%$ PHT at the gyms. During data collection, research staff stood by the entrance of the gyms on a weekday afternoon or evening and asked arriving gym-goers above 16 years of age whether they were going to do weight training (i.e., work with free weights or machines). Those who replied in the affirmative were invited to participate in the study. Gym-goers who agreed to participate were asked to complete a questionnaire. To guarantee anonymity, participants completed the questionnaire anonymously and then placed it in an envelope and sealed it, before returning it to the research staff. For the study, 2631 gymgoers were asked to participate, and 1969 of them agreed (74.8\% response rate). All gyms were located in urban areas; $39 \%$ of the gyms were located in a major city (i.e., more than 200,000 inhabitants), 37\% in a large town (i.e., more than 50,000 inhabitants), and $13 \%$ in a small town (i.e., more than 15,000 inhabitants) [27]. For more details on the data collection, please see study protocol [26].

\section{Measures}

The questionnaire distributed to the participants was based on another questionnaire previously used in a Swedish study measuring anabolic-androgenic steroid use among gym-goers [28]. It included 25 items on background variables, weight training frequency, use of illicit drugs, doping substances, and nutritional supplements, as well as attitude items on doping prevention. 
The questionnaire took 5 to $10 \mathrm{~min}$ to complete. The following measures were included in the current study:

\section{Demographic Factors}

Participants were asked to report their age, sex, employment, and highest educational attainment.

\section{Weight Training Frequency}

Participants were asked "How often do you do weight training at the gym?" Response alternatives were never, less than once a week, once or twice a week, three or four times a week, and five or more times a week.

\section{Use of Illicit Drugs}

Participants were asked "Have you ever used any illicit drugs or prescription drugs without a doctor's order?" Participants were then asked to specify the type of illicit drugs that they had used. Response alternatives were cannabis, amphetamines, cocaine, heroin, hallucinogens, ecstasy, benzodiazepines, or other. Furthermore, participants were asked "Have you used any illicit drugs or prescription drugs without a doctor's order during the past 12 months?" and "Have you used any illicit drugs or prescription drugs without a doctor's order during the past 30 days?"

\section{Use of Doping Substances}

To assess the use of doping substances, participants were asked "Have you ever used any anabolicandrogenic substances, growth hormones or other doping substances without a doctor's order?"

\section{Statistical Analysis}

First, frequencies and proportions of demographic factors and weight training intensity are presented for the whole sample $(n=1969)$. Illicit drug use and associated characteristics are also presented for the whole sample. In a subsequent step, drug characteristics are presented only for those who reported illicit drug use $(n=385)$. Logistic regression models were then calculated in the whole sample $(n=1969)$ to examine associations between illicit drug use and weight training frequency, as well as associations between illicit drug use and use of doping substances. Crude odds ratios (OR) and 95\% confidence intervals $(95 \% \mathrm{CI})$ are presented. Odds ratios were then adjusted; when examining associations between illicit drug use and weight training frequency, odds ratios were adjusted for age and sex. When examining associations between illicit drug use and the use of doping substances, odds ratios were adjusted for age, sex, weight training frequency, and number of illicit drugs used. IBM SPSS Statistics 24.0 was used in all analyses. The STrengthening the Reporting of OBservational studies in Epidemiology (STROBE) guidelines were followed (S1).

\section{Power Analysis}

Previous studies have shown that the effect of prevention programmes is rather low, typically about $15-20 \%$ $[29,30]$. To measure the intervention effect, a power analysis was carried out a priori; a minimum of 40 gyms (20 intervention gyms and 20 control gyms) and a minimum of 1600 participants (800 individuals per condition) were required at each data collection point to achieve a power of $80 \%$ at an alpha level of .05 (two-tailed). In the current pre-intervention study, 27 intervention gyms and 27 control gyms have been enrolled, and a total of 1969 individuals completed the questionnaire.

\section{Ethical approval}

The present study adheres to the criteria of the World Medical Association Declaration of Helsinki, and has been approved by the regional ethical review board of Karolinska Institutet, Sweden (registration number: 2016/142-31/3).

\section{Results}

The present study included 1969 gym-goers from 54 gyms. The sample consisted of a large proportion of males $(65.3 \%)$, and the majority of participants were below 40 years of age. Most gym-goers were employed, had completed secondary or tertiary education, and reported regular weight training. In the total sample of gym-goers, $2.0 \%$ (40) reported having ever used a doping substance (Table 1).

Among the participating gym-goers, 19.6\% (385) reported having ever used an illicit drug or benzodiazepines without a prescription (Table 2). Furthermore, $6.5 \%$ reported that they had done so during the past 12 months and $2.1 \%$ during the past 30 days. Cannabis was the most commonly used illicit drug and had been used by $92.2 \%$ of participants reporting illicit drug use. Between 20 and $25.2 \%$ of the reported illicit drug users had used cocaine, amphetamine, and/or ecstasy. Heroin was the least common illicit drug. Among those who reported illicit drug use, $17.4 \%$ reported having used two drugs and $21.3 \%$ reported having used three or more drugs (Table 3 ). The prevalence of individuals who reported a lifetime use of doping substances was higher among those with prior illicit drug use (5.1\%) than in the total sample. There were statistically significant gender differences in prevalence rates; males demonstrated higher rates of cannabis, amphetamine, cocaine, and ecstasy use. Males also demonstrated significantly higher rates of polysubstance use. Furthermore, there were statistically significant age differences; younger individuals (below age 40) demonstrated higher prevalence rates of 
Table 1 Sample characteristics of gym-goers $(n=1969)$

\begin{tabular}{|c|c|}
\hline \multicolumn{2}{|l|}{$\operatorname{Sex}^{a}$} \\
\hline Male & $63.5 \%(1251$ \\
\hline Female & $35.8 \%(705)$ \\
\hline \multicolumn{2}{|l|}{$\mathrm{Age}^{\mathrm{b}}$} \\
\hline $16-19$ years & $9.3 \%(184)$ \\
\hline 20-29 years & $41.2 \%(811)$ \\
\hline 30-39 years & $19.0 \%(375)$ \\
\hline $40-49$ years & $14.3 \%(281)$ \\
\hline $50-59$ years & $9.9 \%(194)$ \\
\hline 60 years and older & $5.8 \%(114)$ \\
\hline \multicolumn{2}{|l|}{ Occupation ${ }^{c}$} \\
\hline Employed & $71.4 \%(1406$ \\
\hline Unemployed & $3.1 \%(62)$ \\
\hline Studying & $19.2 \%(378)$ \\
\hline Retired & $2.5 \%(49)$ \\
\hline Sick leave & $0.8 \%(16)$ \\
\hline Other & $2.1 \%(42)$ \\
\hline \multicolumn{2}{|l|}{ Highest educational attainment $^{c}$} \\
\hline Primary education & $8.2 \%(162)$ \\
\hline Secondary education & $42.7 \%(841)$ \\
\hline Tertiary education & $31.4 \%(619)$ \\
\hline \multicolumn{2}{|l|}{ Weight training frequency ${ }^{c}$} \\
\hline Never & $1.1 \%(22)$ \\
\hline Less than once a week & $3.8 \%(75)$ \\
\hline Once or twice a week & $23.9 \%(470)$ \\
\hline Three to four times a week & $47.6 \%(937)$ \\
\hline Five or more times a week & $23.5 \%(463)$ \\
\hline \multicolumn{2}{|l|}{ Lifetime use of doping substances } \\
\hline Has ever used a doping substance & $2.0 \%(40)$ \\
\hline
\end{tabular}

cannabis, amphetamine, cocaine, hallucinogen, and ecstasy use and also higher rates of polysubstance use (Table 3).

A logistic regression was performed to examine the relationship between weight training frequency and illicit drug use (Table 4). No statistically significant associations were found, neither in the crude analyses, nor when adjusting for sex and age. Another logistic regression was then performed to assess the relationship between illicit drug use and use of doping substances. The logistic regression model was statistically significant $\left(\chi^{2}=18.391, p<.001, d f=1\right)$, showing that individuals who reported illicit drug use were more than four times more likely to use doping substances compared to individuals without prior illicit drug use.
Table 2 Lifetime drug use among gym-goers $(n=1969)$

\begin{tabular}{ll}
\hline Lifetime drug use & \\
Has ever used drugs & $19.6 \%(385)$ \\
Sex & \\
Male & $71.5 \%(274)$ \\
Female & $28.2 \%(108)$ \\
Age & \\
$16-19$ years & $7.8 \%(30)$ \\
$20-29$ years & $49.7 \%(191)$ \\
$30-39$ years & $26.6 \%(102)$ \\
$40-49$ years & $6.5 \%(25)$ \\
$50-59$ years & $5.5 \%(21)$ \\
60 years and older & $3.9 \%(15)$ \\
Recent illicit drug use & \\
Has used drugs during the past 12 months & $6.5 \%(128)$ \\
Has used drugs during the past 30 days & $2.1 \%(42)$ \\
\hline aMissing information for three individuals \\
${ }^{b}$ Missing information for one individual
\end{tabular}

When adjusting for age, sex, weight training frequency, and number of illicit drugs used, the model remained statistically significant $\left(\chi^{2}=38.514, p<.001, d f=5\right)$. Results showed that individuals who reported illicit drug use were almost three times more likely to use doping substances compared to individuals without prior illicit drug use.

\section{Discussion}

Discussion

In the present study, 1969 gym-goers at 54 gyms in Sweden completed a questionnaire covering the use of illicit drugs and prescription drugs. Results showed that $19.6 \%$ of gym-goers reported having ever used illicit drugs. Moreover, of this group, 6.5\% reported use during the past 12 months and $2.1 \%$ during the past 30 days. Among those who reported illicit drug use, the most commonly used illicit drug was cannabis, followed by cocaine, amphetamine, and ecstasy. Furthermore, 5.1\% of those reported a lifetime use of doping substances. Almost $40 \%$ of those reporting illicit drug use reported polysubstance use. Furthermore, male participants and participants between 16 and 39 years of age demonstrated significantly higher rates of illicit drug use and polysubstance use than female participants and participants above age 40 , respectively.

Our findings are in line with two Swedish populationbased surveys. In a survey from 2008/2009, $18 \%$ of respondents reported having used illicit drugs on at least one occasion in their lives [31]. In a survey from 2012, $3.1 \%$ of respondents had used an illicit drug during the past 12 months and $1.1 \%$ during the past 30 days [32]. 
Table 3 Drug characteristics among gym-goers who reported lifetime drug use $(n=385)$

\begin{tabular}{|c|c|c|c|c|c|c|c|c|c|}
\hline & All drug users & Males $^{a}$ & Females $^{a}$ & $x^{2}$ & $p$ & Age $16-39^{a}$ & Age 40 and over ${ }^{a}$ & $x^{2}$ & $p$ \\
\hline \multicolumn{10}{|c|}{ Lifetime use of illicit drugs } \\
\hline Cannabis & $92.2 \%(355)$ & $67.0 \%(258)$ & $24.7 \%(95)$ & 16.04 & $<0.001$ & 77.4\% (298) & $15.8 \%(56)$ & 41.71 & $<0.001$ \\
\hline Cocaine & $25.2 \%(97)$ & $19.5 \%(75)$ & $5.7 \%(22)$ & 8.07 & 0.018 & $21.8 \%(84)$ & $3.4 \%(13)$ & 13.48 & $<0.001$ \\
\hline Amphetamine & $21.8 \%(84)$ & $16.1 \%(62)$ & $5.5 \%(21)$ & 10.47 & 0.005 & $17.7 \%(68)$ & $4.2 \%(16)$ & 5.07 & 0.024 \\
\hline Ecstasy & $20.0 \%(77)$ & $14.3 \%(55)$ & $5.5 \%(21)$ & 9.28 & 0.010 & $18.4 \%(71)$ & $1.6 \%(6)$ & 18.91 & $<0.001$ \\
\hline Hallucinogens & $13.0 \%(50)$ & $9.6 \%(37)$ & $3.4 \%(13)$ & 2.33 & 0.312 & $11.4 \%(44)$ & $1.3 \%(5)$ & 9.43 & $<0.001$ \\
\hline Benzodiazepines & $8.6 \%(33)$ & $6.8 \%(26)$ & $1.8 \%(7)$ & 3.26 & 0.196 & $7.0 \%(27)$ & $1.6 \%(6)$ & 2.25 & 0.133 \\
\hline Heroin & $1.6 \%(6)$ & $1.6 \%(6)$ & $0.0 \%(0)$ & 3.41 & 0.182 & $0.8 \%(3)$ & $0.8 \%(3)$ & 1.14 & 0.286 \\
\hline Other & $3.1 \%(12)$ & $2.9 \%(11)$ & $0.3 \%(1)$ & 4.05 & 0.132 & $2.6 \%(11)$ & $0.3 \%(1)$ & 2.71 & 0.100 \\
\hline \multicolumn{10}{|c|}{ Number of illicit drugs used (lifetime) } \\
\hline One drug & $59.7 \%(230)$ & $41.3 \%(159)$ & $18.2 \%(70)$ & 15.55 & 0.001 & $48.3 \%(186)$ & $11.4 \%(44)$ & 41.73 & $<0.001$ \\
\hline Two drugs & $17.4 \%(67)$ & $13.5 \%(52)$ & $3.9 \%(15)$ & & & $14.8 \%(57)$ & $2.3 \%(9)$ & & \\
\hline Three or more drugs & $21.3 \%(82)$ & $15.8 \%(61)$ & $5.2 \%(20)$ & & & $19.0 \%(73)$ & $2.6 \%(10)$ & & \\
\hline \multicolumn{10}{|c|}{ Lifetime use of doping substances } \\
\hline Doping substances & $4.9 \%(19)$ & $6.4 \%(17)$ & $1.9 \%(2)$ & 3.05 & 0.218 & $5.4 \%(17)$ & $3.4 \%(2)$ & 0.40 & 0.529 \\
\hline
\end{tabular}

${ }^{a}$ Missing information for one individual

Training at gyms is typically a health-promoting behavior; hence, it could be hypothesized that the estimates in our sample would be lower than the rates found in the general population. However, our results pointed to a slightly higher prevalence of illicit drug use among gymgoers. The elevated rates in our study could be explained by age and sex differences in the samples; our study included more males and more individuals from younger age categories, where illicit drug use is generally more prevalent [31, 32].

Conversely, participants in the present study reported a lower lifetime prevalence of illicit drug use as compared to the European average. In the European Union, approximately $25 \%$ of 15 - to 64-year-olds are estimated to have used an illicit drug [33]. Studies consistently indicate lower estimates of illicit drug use in Sweden compared to many countries [34-36], which also could be reflected among gym-goers [24, 25]. Further research is needed to specifically examine the use of illicit drugs and prescription drugs (beyond benzodiazepines) in gym settings and to assess between-country differences as well as associations with demographic factors. Prevalence rates in our study were higher than rates among elite athletes in
Europe and Australia [17, 18, 21]. Higher estimates of illicit drug use among gym-goers might be expected, however, as elite athletes generally have a healthier lifestyle and are also subject to anti-doping tests, which may have a deterrent effect on illicit drug use [18].

Two studies have examined the use of illicit drugs among gay male gym-goers in New York and London, respectively. In these studies, prevalence rates were markedly higher than in our study; in the New York study, estimates ranged between 6\% (for hallucinogen use) and 35\% (for inhalant nitrite use) during the past 6 months [24]. Among the men recruited from London gyms, 56\% reported having used an illicit drug during the past 12 months [25]. It was proposed that these studies largely reflected a specific subculture among gay and bisexual men who frequented clubs and engaged in risk behaviors (i.e., substance use and sexual risk behavior), which could explain the higher prevalence rates.

The most commonly used illicit drugs in our study were cannabis, cocaine, amphetamine, ecstasy, and hallucinogens-drugs that can be used both as training aids or "body image drugs," or recreationally as so-called club drugs [37-40]. Moreover, approximately $40 \%$ of the illicit

Table 4 Associations between illicit drug use and weight training frequency and use of doping substances, respectively $(n=1969)$

\begin{tabular}{|c|c|c|c|c|c|c|}
\hline & \multicolumn{3}{|c|}{ Crude } & \multicolumn{3}{|c|}{ Adjusted } \\
\hline & $\overline{\mathrm{OR}}$ & $95 \% \mathrm{Cl}$ & $p$ & $\overline{\mathrm{OR}}$ & $95 \% \mathrm{Cl}$ & $p$ \\
\hline Weight training frequency & 1.07 & $0.94-1.23$ & 0.296 & $0.90^{\mathrm{a}}$ & $0.78-1.04$ & 0.143 \\
\hline Use of doping substances & 4.40 & $2.28-8.46$ & $p<0.001$ & $2.99^{b}$ & $1.16-7.66$ & $p<0.023$ \\
\hline
\end{tabular}

OR odds ratio $95 \%, \mathrm{Cl} 95 \%$ confidence intervals

${ }^{a}$ Adjusted for sex and age

${ }^{\mathrm{b}}$ Adjusted for sex, age, weight training frequency, and number of drugs used 
drug users in our sample reported polysubstance use, and the rates were significantly higher among younger participants and males. Our results could also have captured a group of young adult males who focus on physical appearance and engage in partying and risk behaviors, comparable to the gay men in the gym studies discussed above. It has been suggested that drug use practices and weight training in a male "body subculture" can be understood as a way to construct a masculine identity and to achieve an idealized male body [41]. Our estimates were higher than the estimates in a study of anabolic substance use among 611 visitors to German fitness centers, where $15.9 \%$ reported using other illicit drugs [42]. Almost all participants in our study engaged in weight training, as opposed to $25 \%$ of the respondents in the German study. Again, the higher prevalence rates in our study could support the notion of a physical achievement-oriented group who engage in weight training and use illicit substances for ergogenic and/or recreational purposes.

In our study, however, we found no associations between weight training frequency and illicit drug use. Prior research on the association between physical activity and illicit drug use is mixed: Some studies suggest that the degree of sporting activity is negatively associated with substance use [43]. Others point to a curvilinear link between sporting activities and illicit drug use, i.e., that inactive and intensive levels are associated with greater use of illicit drugs than moderate levels are, particularly for strength sports (weightlifting and body-building) [19]. However, these studies have largely been based on adolescent populations, and it has been proposed that the relationship between physical activity and illicit drug use is affected by age [19], which could explain our differing results.

The overall prevalence of the lifetime use of doping substances (i.e., anabolic-androgenic substances and growth hormones) was lower in our total sample than in other gym samples [28, 42, 44-46]. Nonetheless, our results showed a threefold higher in odds of doping use among people who had reported illicit drug use as compared to non-users. Previous research has pointed to a strong relationship between use of doping substances and use of other illicit drugs [14, 47-49]. Illicit drugs may be used to increase or decrease the effects of anabolic-androgenic steroids (e.g., as pain relief to increase energy levels or to promote sleep) [6], and it has been proposed that doping prevention efforts should therefore address other illicit drugs as well [6]. The European Commission Group of Experts on Anabolic Androgenic Steroid Use in Recreational Sports has identified gyms as important target arenas for preventive efforts and has also suggested three key elements that should be included in research to inform policy, practice, and interventions: information on doping prevalence, use of other illicit drugs, and determinants and correlates [11].

\section{Strengths and Limitations}

The present study has both strengths and limitations that should be taken into account when interpreting the findings. One important strength is that we included a large sample of men and women and that participants were recruited from 54 gyms across the country. Limitations include a possible underestimation of illicit drug prevalence rates due to a higher degree of attrition among individuals who use illicit drugs or to recollection bias, social desirability, or fear that reported illicit drug use may attract unwanted attention to the gym [50]. Males and individuals under age 40 made up a large proportion of participants, which could limit the generalizability of the findings. Furthermore, the questionnaire was distributed on weekday afternoons and evenings, and only individuals who engaged in weight training were invited to participate, which could limit generalizability further. Although the questionnaire has been used in a prior study [28], its psychometric properties have not been validated. Another limitation was that the study was cross-sectional; thus, we could not establish causality in the association between illicit drug and doping use.

\section{Conclusions}

Our study examined illicit drug use in a large sample of male and female adult gym-goers. Illicit drug use estimates in our study were slightly elevated in comparison to estimates in population-based studies in Sweden [31,32] and could simply reflect illicit drug use in the general population. This may seem contradictory, however, as training at gyms is typically considered a health-promoting behavior and prevalence rates could thus be expected to be lower among gym-goers. Our findings show that a substantial proportion of young adult males who lift weights have used several illicit drugs. This suggests that illicit drug use among sportspeople, possibly for ergogenic or analgesic purposes, is a public health problem not limited to elite athletes $[17,18,21]$. A proportion of younger recreational sportspeople may be at risk of developing substance abuse problems (including doping substances), yet there are few arenas on which young individuals can be reached other than nightlife settings and universities [50-52]. Previous research shows that young people who party frequent gyms to socialize, to offset the effects of substance use, or to purchase illicit drugs [53]. Gyms could thus provide an additional innovative setting for intervention and prevention efforts targeting doping and illicit drug use, because such establishments already deal with health promotion and do not allow on-site alcohol consumption.

\section{Abbreviations}

100\% PHT: 100\% Pure Hard Training; 95\% Cl: 95\% confidence intervals;

OR: Odds ratios; PRODIS: Prevention of Doping in Sweden; STAD: Stockholm Prevents Alcohol and Drug Problems; STROBE: STrengthening the Reporting of OBservational studies in Epidemiology guidance 


\section{Acknowledgements}

The authors are grateful to Viveca Andersson, Kamilla Nylund, and Nicklas Kartengren for their help with the data collection and contributions to the manuscript, and to the PRODIS network and the participating gyms for their cooperation.

\section{Funding}

The study is funded by The Public Health Agency of Sweden (Grant Number 05522-2014-6.2). The funders play no role in the design of the study; the collection, analysis, and interpretation of the data; or in the writing of the manuscript.

\section{Availability of data and materials}

The data will not be shared due to participant confidentiality.

\section{Authors' contributions}

$J G$ conceived of the original idea and JG and ASB obtained the funding for the study. YM, JG, and ASB planned and designed the current study. YM carried out all the analyses, and YM, JG, and ASB interpreted the data. YM prepared the manuscript with the contribution of ASB and JG. All authors read and approved of the final manuscript.

\section{Ethics approval and consent to participate}

The present study adheres to the criteria of the World Medical Association Declaration of Helsinki, and has been approved by the regional ethical review board of Karolinska Institutet, Sweden (registration number: 2016/142-31/3).

\section{Consent for publication}

Not applicable

\section{Competing interests}

Yasmina Molero, Ann-Sofie Bakshi, and Johanna Gripenberg declare that they have no conflict of interest.

\section{Publisher's Note}

Springer Nature remains neutral with regard to jurisdictional claims in published maps and institutional affiliations.

\section{Received: 26 April 2017 Accepted: 11 August 2017}

Published online: 29 August 2017

\section{References}

1. Eurobarometer, Special. Eurobarometer 72.3. Sport and Physical Activity, Wave EB80 2. Brussels: Directorate General Education and Culture; 2010.

2. Facts about physical activity [Internet]. 2014. Available from: https://www. cdc.gov/physicalactivity/data/facts.htm. Accessed 28 Feb 2017.

3. Facts on Health \& Fitness Clubs [Internet]. 2016. https://www.statista.com/ topics/1141/health-and-fitness-clubs/. Accessed 28 Feb 2017.

4. Lee IM, Shiroma EJ, Lobelo F, Puska P, Blair SN, Katzmarzyk PT. Effect of physical inactivity on major non-communicable diseases worldwide: an analysis of burden of disease and life expectancy. Lancet (London, England). 2012:380(9838):219-29.

5. Baker JS, Graham MR, Davies B. Steroid and prescription medicine abuse in the health and fitness community: a regional study. European journal of internal medicine. 2006;17(7):479-84.

6. Sagoe D, McVeigh J, Bjornebekk A, Essilfie MS, Andreassen CS, Pallesen S Polypharmacy among anabolic-androgenic steroid users: a descriptive metasynthesis. Subst Abuse Treat Prev Policy. 2015:10:12.

7. Sjoqvist F, Garle M, Rane A. Use of doping agents, particularly anabolic steroids, in sports and society. Lancet (London, England). 2008;371(9627): 1872-82.

8. Dodge T, Hoagland MF. The use of anabolic androgenic steroids and polypharmacy: a review of the literature. Drug Alcohol Depend. 2011; 114(2-3):100-9.

9. Connor JP, Gullo MJ, White A, Kelly AB. Polysubstance use: diagnostic challenges, patterns of use and health. Current opinion in psychiatry. 2014; 27(4):269-75.

10. Midanik LT, Tam TW, Weisner C. Concurrent and simultaneous drug and alcohol use: results of the 2000 National Alcohol Survey. Drug Alcohol Depend. 2007;90(1):72-80.
11. Backhouse S, Collins C, Defoort Y, McNamee M, Parkinson A, Sauer M, et al. Study on doping prevention: a map of legal, regulatory and prevention practice provisions in EU 28. 2014.

12. Denham BE. Association between narcotic use and anabolic-androgenic steroid use among American adolescents. Subst Use Misuse. 2009;44(14): 2043-61.

13. Nyberg F, Hallberg M. Interactions between opioids and anabolic androgenic steroids: implications for the development of addictive behavior. Int Rev Neurobiol. 2012;102:189-206.

14. Kanayama G, Pope HG, Cohane G, Hudson Jl. Risk factors for anabolicandrogenic steroid use among weightlifters: a case-control study. Drug Alcohol Depend. 2003;71(1):77-86.

15. Laure $P$, Lecerf $T$, Friser $A$, Binsinger $C$. Drugs, recreational drug use and attitudes towards doping of high school athletes. Int J Sports Med. 2004; 25(2):133-8

16. Moore MJ, Werch CE. Sport and physical activity participation and substance use among adolescents. The Journal of adolescent health : official publication of the Society for Adolescent Medicine. 2005;36(6):486-93.

17. Thevis M, Sauer M, Geyer H, Sigmund G, Mareck U, Schanzer W. Determination of the prevalence of anabolic steroids, stimulants, and selected drugs subject to doping controls among elite sport students using analytical chemistry. J Sports Sci. 2008;26(10):1059-65.

18. Strano Rossi S, Botre F. Prevalence of illicit drug use among the Italian athlete population with special attention on drugs of abuse: a 10-year review. J Sports Sci. 2011;29(5):471-6.

19. Peretti-Watel P, Beck F, Legleye S. Beyond the U-curve: the relationship between sport and alcohol, cigarette and cannabis use in adolescents. Addiction. 2002;97(6):707-16.

20. Brisola-Santos MB, Gil F, Sampaio-Junior B, Marin MCD, de Andrade AG, Richter KP, et al. Prevalence and correlates of cannabis use among athletes—a systematic review. Am J Addict. 2016;(7):518-28.

21. Harcourt PR, Unglik $H_{1}$ Cook JL. A strategy to reduce illicit drug use is effective in elite Australian football. Br J Sports Med. 2012:bjsports-2012091329.

22. Momaya A, Fawal M, Estes R. Performance-enhancing substances in sports: a review of the literature. Sports Med. 2015:45(4):517-31.

23. Reardon $\mathrm{CL}$, Creado S. Drug abuse in athletes. Substance Abuse and Rehabilitation. 2014:5:95-105.

24. Halkitis PN, Moeller RW, Siconolfi DE, Jerome RC, Rogers M, Schillinger J. Methamphetamine and poly-substance use among gym-attending men who have sex with men in New York City. Annals of behavioral medicine : a publication of the Society of Behavioral Medicine. 2008;35(1):41-8.

25. Bolding G, Hart G, Sherr L, Elford J. Use of crystal methamphetamine among gay men in London. Addiction. 2006;101(11):1622-30.

26. Molero Y, Gripenberg J, Bakshi AS. Effectiveness and implementation of a community-based prevention programme targeting anabolic androgenic steroid use in gyms: study protocol of a quasi-experimental control group study. BMC sports science, medicine and rehabilitation. 2016;8:36.

27. Swedish Association of Local Authorities and Regions [Statens Kommuner och Landsting]. Division of municipalities 2017 [Kommungruppsindelning 2017]. Stockholm: Sveriges Kommuner och Landsting, ISBN: 978-91-7585455-7; 2016

28. Leifman H, Rehnman C, Sjoblom E, Holgersson S. Anabolic androgenic steroids - use and correlates among gym users - an assessment study using questionnaires and observations at gyms in the Stockholm region. Int J Environ Res Public Health. 2011;8(7):2656-74.

29. Skärstrand E. Prevention of alcohol and drug problems among adolescents: evaluating a Swedish version of the Strengthening Families Program: Inst för folkhälsovetenskap/Dept of Public Health Sciences. Solna: Karolinska Institutet; 2010

30. Strandberg A. Evaluation of a Swedish parental prevention program: youth drunkenness, alcohol-specific parenting and gender differences: Inst för folkhälsovetenskap/Dept of Public Health Sciences. Solna: Karolinska Institutet; 2014.

31. The Public Health Agency of Sweden [Folhälsomyndigheten]. Drug use in Sweden [Narkotikabruket i Sverige]. Östersund: Folkhälsomyndigheten, ISBN: 978-91-7257-713-8; 2010

32. Ramstedt M, Sundin E, Landberg J, Raninen J. Alcohol, narcotics, doping, and tobacco use and its negative consequences in the Swedish population - a study focused on misuse, abuse, and other problems related to alcohol, narcotics, doping, and tobacco [ANDT-bruket och dess negativa 
konsekvenser i den svenska befolkningen 2013—en studie med fokus på missbruk och beroende samt problem för andra än brukaren relaterat till alkohol, narkotika, doping och tobak]. Stockholm: STAD; 2014. ISBN: 978-9185997-24-4.

33. European Monitoring Centre for Drugs and Drug Addiction. European drug report 2016: trends and developments. Luxembourg; 2016.

34. Degenhardt L, Bucello C, Calabria B, Nelson P, Roberts A, Hall W, et al. What data are available on the extent of illicit drug use and dependence globally? Results of four systematic reviews. Drug Alcohol Depend. 2011; 117(2-3):85-101.

35. Degenhardt L, Hall W. Extent of illicit drug use and dependence, and their contribution to the global burden of disease. Lancet (London, England). 2012;379(9810):55-70.

36. The Public Health Agency of Sweden (Folhälsomyndigheten). The 2013 national report (2012 data) to the EMCDDA by the Reitox National Focal Point Sweden. New development and trends. Östersund: STATENS FOLKHÄLSOINSTITUT A; 2013. p. 2.

37. Kanayama G, Hudson Jl, Pope HG Jr. Illicit anabolic-androgenic steroid use. Horm Behav. 2010;58(1):111-21.

38. Clarkson PM, Thompson HS. Drugs and Sport. Sports Med. 1997;24(6):366-84.

39. Huestis MA, Mazzoni I, Rabin O. Cannabis in Sport. Sports Med. 2011;41(11): 949-66.

40. Kanayama G, Pope HG Jr, Hudson J.. "Body image" drugs: a growing psychosomatic problem. Psychother Psychosom. 2001;70(2):61-5.

41. Andreasson J. Reconceptualising the gender of fitness doping: performing and negotiating masculinity through drug-use practices. Soc Sci. 2015;4(3): $546-62$

42. Striegel H, Simon P, Frisch S, Roecker K, Dietz K, Dickhuth HH, et al. Anabolic ergogenic substance users in fitness-sports: a distinct group supported by the health care system. Drug Alcohol Depend. 2006;81(1):11-9.

43. Korhonen T, Kujala UM, Rose RJ, Kaprio J. Physical activity in adolescence as a predictor of alcohol and illicit drug use in early adulthood: a longitudinal population-based twin study. Twin research and human genetics : the official journal of the International Society for Twin Studies. 2009;12(3):261-8.

44. Sagoe D, Molde H, Andreassen CS, Torsheim T, Pallesen S. The global epidemiology of anabolic-androgenic steroid use: a meta-analysis and meta-regression analysis. Ann Epidemiol. 2014;24(5):383-98.

45. Nakhaee MR, Pakravan F, Nakhaee N. Prevalence of use of anabolic steroids by bodybuilders using three methods in a city of Iran. Addiction \& health. 2013;5(3-4):77.

46. Alsaeed I, Alabkal JR. Usage and perceptions of anabolic-androgenic steroids among male fitness centre attendees in Kuwait —a cross-sectional study. Subst Abuse Treat Prev Policy. 2015;10:33.

47. Skarberg K, Nyberg F, Engstrom I. Multisubstance use as a feature of addiction to anabolic-androgenic steroids. Eur Addict Res. 2009;15(2):99-106.

48. Arvary D, Pope HG Jr. Anabolic-androgenic steroids as a gateway to opioid dependence. N Engl J Med. 2000;342(20):1532.

49. Kanayama G, Cohane GH, Weiss RD, Pope HG. Past anabolic-androgenic steroid use among men admitted for substance abuse treatment: an underrecognized problem? The Journal of clinical psychiatry. 2003;64(2): $156-60$

50. Gripenberg-Abdon J, Elgan TH, Wallin E, Shaafati M, Beck O, Andreasson S. Measuring substance use in the club setting: a feasibility study using biochemical markers. Subst Abuse Treat Prev Policy. 2012;7:7.

51. Nordfjaern T, Bretteville-Jensen AL, Edland-Gryt M, Gripenberg J. Risky substance use among young adults in the nightlife arena: an underused setting for risk-reducing interventions? Scandinavian journal of public health. 2016. [Epub ahead of print].

52. Bullock S. Alcohol, drugs and student lifestyle: a study of the attitudes, beliefs and use of alcohol and drugs among Swedish university students. Stockholm: SoRAD - Research Report nr 21 ISBN: 91-975134-7; 2004

53. Lindsay J. 'Partying hard', 'partying sometimes' or 'shopping': young workers' socializing patterns and sexual, alcohol and illicit drug risk taking. Critical Public Health. 2003;13(1):1-14.

\section{Submit your manuscript to a SpringerOpen ${ }^{\circ}$ journal and benefit from:}

- Convenient online submission

- Rigorous peer review

- Open access: articles freely available online

- High visibility within the field

- Retaining the copyright to your article

Submit your next manuscript at $>$ springeropen.com 